\title{
Familial Alzheimer's Disease and Recessive Modifiers
}

\author{
Jorge I. Vélez ${ }^{1}$ (1) $\cdot$ Francisco Lopera $^{2}$ (D) $\cdot$ Claudia T. Silva $^{2}$ (D) $\cdot$ Andrés Villegas $^{2} \cdot$ Lady G. Espinosa $^{3} \cdot$ Oscar M. Vidal $^{1}$ (D) \\ Claudio A. Mastronardi ${ }^{3}$ (D) Mauricio Arcos-Burgos ${ }^{4}$ (10)
}

Received: 24 July 2019 / Accepted: 22 September 2019 / Published online: 29 October 2019

(C) The Author(s) 2019

\begin{abstract}
Alzheimer's disease (AD) is progressive brain disorder that affects $\sim 50$ million people worldwide and has no current effective treatment. $\mathrm{AD}$ age of onset (ADAOO) has shown to be critical for the identification of genes that modify the appearance of $\mathrm{AD}$ signs and symptoms in a specific population. We clinically characterized and whole-exome genotyped 71 individuals with AD from the Paisa genetic isolate, segregating the (PSEN1) E280A dominant fully penetrant mutation, and analyzed the potential recessive effects of $\sim 50,000$ common functional genomic variants to the ADAOO. Standard quality control and filtering procedures were applied, and recessive single- and multi-locus linear mixed-effects models were used. We identified genetic variants in the $S L C 9 C 1, C S N 1 S 1$, and LOXL4 acting recessively to delay ADAOO up to $\sim 11, \sim 6$, and $\sim 9$ years on average, respectively. In contrast, the CC recessive genotype in marker DHRS4L2-rs2273946 accelerates ADAOO by $\sim 8$ years. This study, reports new recessive variants modifying ADAOO in PSEN1 E280A mutation carriers. This set of genes are implicated in important biological processes and molecular functions commonly affected by genes associated with the etiology of AD such as $A P P, A P O E$, and $C L U$. Future functional studies using modern techniques such as induced pluripotent stem cells will allow a better understanding of the over expression and down regulation of these recessive modifier variants and hence the pathogenesis of $\mathrm{AD}$. These results are important for prediction of $\mathrm{AD}$ and ultimately, substantial to develop new therapeutic strategies for individuals at risk or affected by AD.
\end{abstract}

Keywords Alzheimer's disease · PSEN1 · Age of onset · Recessive Mutations · Genetic Isolates · Genetic Interactions

\section{Introduction}

The global incidence and prevalence of Alzheimer's disease (AD) are increasing at alarming rates. Without intervention, 1

Jorge I. Vélez, Francisco Lopera, Claudio A. Mastronardi and Mauricio Arcos-Burgos contributed equally to this work.

Electronic supplementary material The online version of this article (https://doi.org/10.1007/s12035-019-01798-0) contains supplementary material, which is available to authorized users.

Mauricio Arcos-Burgos

mauricio.arcos@udea.edu.co

Universidad del Norte, Barranquilla, Colombia

2 Neuroscience Research Group, University of Antioquia, Medellín, Colombia

3 INPAC Research Group, Fundación Universitaria Sanitas, Bogotá, Colombia

4 Grupo de Investigación en Psiquiatría (GIPSI), Departamento de Psiquiatría, Instituto de Investigaciones Médicas (IIM), Facultad de Medicina, Universidad de Antioquia, Medellín, Colombia in 85 people worldwide will develop AD by 2050 [1]. Remarkably, the delay of the AD age of onset (ADAOO) by 1 year would result in $\sim 9$ million fewer cases of the disease worldwide by 2050 [2]. Therefore, it is imperative to advance our efforts in therapeutic and preventative strategies, not only to cure, but also to delay the ADAOO.

Several studies show that linear and non-linear gene variant interactions modify the ADAOO affecting significantly the cognitive decline, changing the AD natural history, and delaying the ADAOO even by more than a decade [3-10]. Genetic epistasis (non-linear interaction among genes) is shaped by the genetic structure of the population and consequently by the individual genomic structure. In the case of genetic isolates, the steady increase in homozygosis (deficit of heterozygosis) not only outlines and defines population micro differentiation (substructure), but plays a pivotal role in shaping individual complex phenotypes [11]. In this vein, it was around 30 years ago that our group first made the clinical and genetic characterization of the world-over largest pedigree segregating $\mathrm{AD}$ ascertained from a genetic isolate. More than 5,000 individuals grouped into 25 families, half of whom 
will develop $\mathrm{AD}$ at an early age, constitute this pedigree $[6$, 12]. Most people in this pedigree live in and around Yarumal, a town engraved in the Andean mountains of Northeast Colombia. People inhabiting this region call themselves "Paisas" [11]. Individuals belonging to the "Paisa pedigree," affected by AD, carry a deleterious variant in the Presenilin 1 (PSEN1) gene and most will develop dementia before their 50th birthday (we have coined the term the Paisa pedigree, making reference to the clan cluster with this homogeneous form of $\mathrm{AD}$ ) [12]. This variant, a GAA[Glu] $\rightarrow$ GCA[Ala] substitution at position 73,664,808 in chromosome 14 , is often referred to as the E280A or Paisa mutation.

The founder effect of this pedigree dates from the time Spanish Conquistadors colonized Colombia during the 16th century $[6,12]$. To date, individuals grouped into these families are recognized as descendants of the original founder [11]. This pedigree is a unique resource for neurological and genetic research into $\mathrm{AD}$ as it contains exhaustive and detailed medical records from thousands of individuals, with multiple and prospective follow-ups, including neurological evaluations, neuropsychological tests, biomarkers, and image data [13].

Alzheimer's disease recurs within families more often than expected by chance alone. It is well accepted that $\mathrm{AD}$ follows an autosomal dominant pattern of inheritance, especially in families of the Paisa community suffering from the most severe form of $\mathrm{AD}$ [14]. However, several studies have also dissected mutations and duplications, particularly in the Apoliprotein $(A P P)$ gene, that act in a recessive fashion to dramatically change AD susceptibility [15-19]. Recessive contributions can be particularly inferred in populations exhibiting high degrees of consanguinity and higher prevalence of disease than the general population [20] such as the Paisa genetic isolate in Colombia [11] and the Wadi Ara population in Israel [21, 22]. However, there is no evidence of the potential role that these, nor other recessive mutations, may play as $\mathrm{ADAOO}$ modifiers in individuals with $\mathrm{AD}$ carrying the E280A mutation.

In previous reports, we tested the influence of dominant major genes interacting with the PSEN1-E280A mutation to modify ADAOO. However, the presence of recessive interactions of functional variants on ADAOO is yet to be explored. This is legitimate problem, given (1) the significant inbreeding that is present in this genetic isolate and (2) the increasing evidence that recessive mutations may be important in AD neuropathology. In this manuscript, we tackle the hypothesis that the homozygosis structure at the individual level in carriers of the E280A mutation underpins the major gene recessive epistasis modifying the ADAOO. Given that genes encoding enzymes and blood-transported substrates act recessively, the definition of such themes might be suitable to outline potential therapeutic targets.

\section{Subjects and Methods}

\section{Patients, DNA Extraction, and Genotyping}

Detailed clinical, paraclinical, and ascertainment procedures, applied to this pedigree, have been presented elsewhere [12, 23, 24]. The Ethics Committee of the University of Antioquia approved this study (Protocol 1115- 408-20543). Informed consent was obtained from all participants. A total of 71 individuals with the E280A mutation were included for the analysis. Genomic DNA was extracted from peripheral blood from all patients and processed by the Australian Genome Facility (Melbourne, VIC, Australia). Seventy-one individuals with $\mathrm{AD}$ from the E280A pedigree were genotyped; 57 were subject to whole-exome genotyping (WEG) using Illumina ${ }^{\circledR}$ HumanExome BeadChip-12v1_A and 14 underwent wholeexome capture (WEC). A detailed description of the genotyping, capture, and WEG and WEC methods has been presented elsewhere [5]. Samples with SNPs call rates below Illumina's ${ }^{\circledR}$ expected $99 \%$ were excluded.

\section{Genetic, Statistical, and Bioinformatics Analyses}

\section{Quality Control, Filtering, and Classification of Functional Variants}

After importing the genetic data to Golden Helix's® SVS 8.3.0, a single genetic data file was constructed by merging the exonic variants from both the WEG and WEC platforms. Genotypes for 71 individuals from the E280A pedigree were obtained, and quality control subsequently performed using the following exclusion criteria: $(i)$ deviations from Hardy-Weinberg equilibrium with $P$ values < $0.05 / m$ (where $m$ is the number of markers included for analysis); (ii) genotype call rate $<90 \%$; (iii) presence of one or $>2$ alleles. Genotype and allelic frequencies were estimated by maximum likelihood. Following previous recommendations [25], variants with a minor allele frequency $(\mathrm{MAF}) \geq 0.01$ were classified as common and as rare otherwise. Rare variants were excluded from the analysis. Exonic variants with potential functional effect were determined using the functional prediction information available in the dbNSFP_NS_Functional_Predictions GRCh_37 annotation track [26]. The dbNSFP is an integrated database of functional annotations from multiple sources for the comprehensive collection of human nonsynonymous SNPs (NSs). Its current version includes a total of $82,832,027$ NSs and splice site SNPs, and compile prediction scores from 14 prediction algorithms including SIFT, Polyphen2, LRT, MutationTaster, MutationAssessor, FATHMM, MetaSVM, MetaLR, VEST, PROVEAN, FATHMM-MKL coding and fitCons, eight conservation scores (phyloP46way_primate, 
phyloP46way_placental, phyloP100way_vertebrate, phastCons46way_primate, phastCons46way placental, phastCons100way_veterbrate, GERP++ and SiPhy), and other function annotations [27-29]. This filter is fully implemented in the Golden Helix ${ }^{\circledR}$ SVS 8.3.0 Variant Classification module. This module was also used to examine interactions between variants and gene transcripts to classify variants based on their potential effect on genes. Variants were classified according to their position in a gene transcript. In addition, variants in coding exons were further classified according to their effect on the gene's protein sequence.

\section{GWAS Analysis of Common Variants}

We studied the association between common exonic functional variants (CEFVs) and ADAOO using single- and multi-locus recessive linear mixed-effect models (LMEMs) [30] with up to 10 steps in the backward/ forward optimization algorithm. Both types of models are implemented in Golden Helix ${ }^{\circledR}$ SVS 8.3.0. The advantage of these models is the inclusion of both fixed (genotype markers, sex, and years of education) and random effects (family or population structure); the latter to account for potential inbreeding by including a kinship matrix (that is, the identity-by-descent [IBD], which in our case was estimated between all pairs of individuals using markers excluded from the final analysis after linkage disequilibrium [LD] pruning).

A single-locus LMEM assumes that all loci have a small effect on the trait, while a multi-locus LMEM assumes that several loci have a large effect on the trait [30]. The optimal model was selected using a comprehensive exploration of multiple criteria including the Extended Bayes Information Criteria $(e B I C)$, the Modified Bayes Information Criteria $(m B I C)$, and the Multiple Posterior Probability of Association (mPPA). After the estimation process using the forward/ backward algorithm concluded, the estimated coefficients $\hat{\beta}_{1}$, $\hat{\beta}_{2}, \ldots, \hat{\beta}_{m}$ were extracted and a hypothesis test of the form $H_{0, i}: \beta_{i}=0$ vs. $H_{1, i}: \beta_{i} \neq 0$ was performed for the $i$ th CEFVs to obtain the corresponding $P$ value, $P_{i}(i=1,2, \ldots, m)$. The collection $P_{1}, P_{2}, \ldots, P_{m}$ was subsequently corrected for multiple testing using the false discovery rate (FDR) [31, 32] using $\mathrm{R}$ [33].

\section{Biological Relatedness Between Candidate and Core Genes}

We used the Human Gene Connectome (HGC) database [34] to quantify the biological relatedness between ADAOO modifier genes identified in our set of PSEN1 E280A mutation carriers and genes reported to cause this form of AD. The HGC is more effectively applied when seeking to identify
Mendelian disease-causing genes. Thus, using the HGC database could disclose some relevant information pointing cryptic networks out from the genes reported by our GWAS analysis of common variants (see "Subjects and Methods" section). The rationale of the HGC is to prioritize candidate genes on the basis of their functional relevance to the $\mathrm{AD}$ phenotype. Candidate genes were chosen on the basis of their quantitative relatedness or biological distance to genes already established as having functional importance in $\mathrm{AD}$. Biological distances [34] were calculated between genes identified in our association analyses and those previously identified in AD. To evaluate the significance of these distances, $P$ values are estimated via random permutation of pairwise gene interactions in the HGC database.

\section{Results}

\section{Subjects}

Demographic data, including age, ADAOO, gender, and schooling of individuals with familial and sporadic AD have been presented comprehensively in previous manuscripts [3, 5]. Briefly, 71 patients with AD carrying the E280A mutation and from the extremes of the ADAOO distribution (44 women [62\%] and 27 men [38\%]) were clinically evaluated and genotyped using either WEG or WEC (see "Methods" section). Years of education ranged from 0 to 19 years $(6 \pm 4.24$ years, $n$ $=57) ; 4(7 \%)$ individuals never attended school, and 28 (49.1\%), 21 (36.9\%), and 4 (7\%) attended but not necessarily completed elementary school (grades 1 to 5), high school (grades 6 to 11, inclusive), and tertiary education, respectively. The ADAOO (mean \pm SD) was $47.8 \pm 5.8$ years, with no statistically significant differences by gender (female $47.6 \pm$ 6.1 ; male $48.4 \pm 5.5, P=0.55)$ and education groups $\left(F_{3,53}=\right.$ $2.721, P=0.053)$.

\section{Quality Control and Genetic Population Structure}

After quality control, assembling, and filtering, a total of 49,087 common and rare variants with potential functional effects remained for genetic analyses (Fig. 1a). To control for potential genetic population stratification (population subdivision), we estimated the $F_{\mathrm{st}}$ statistic of S. Wright. The $F_{\mathrm{st}}$ value is 0.0187 for our cohort, which suggests no microdifferentiation.

\section{Recessive Variants Modifying ADAOO}

A recessive multi-locus LMEM with four steps in the backward/forward optimization algorithm was selected as the optimal model best explaining the ADAOO variance ( $>65 \%$ in total; Fig. 1b). The application of a single- 
a

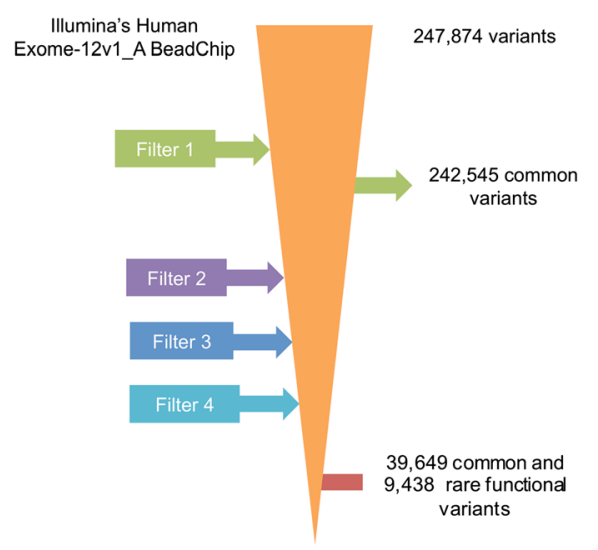

b

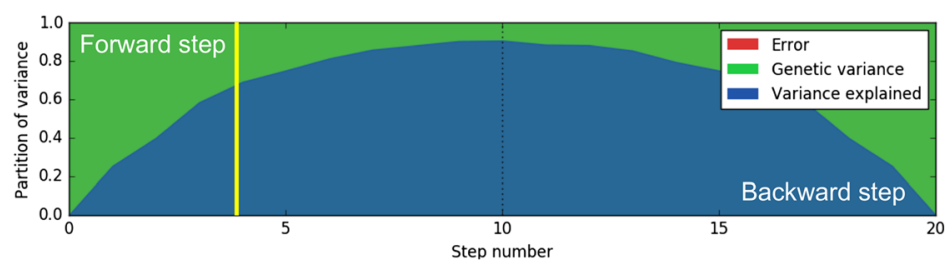

C

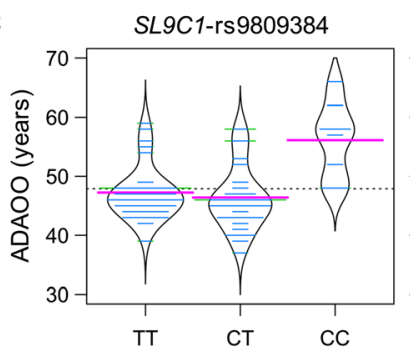

d
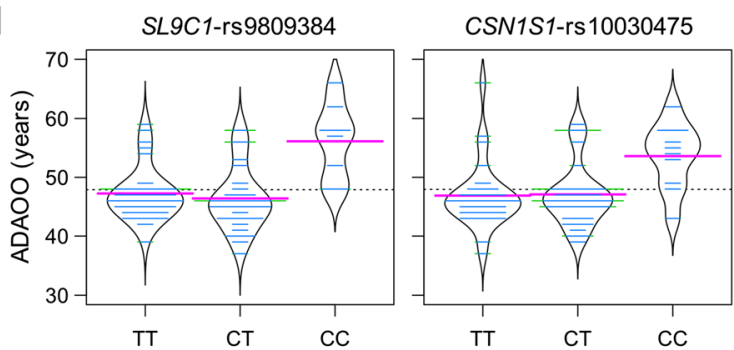

LOXL4-rs33995374

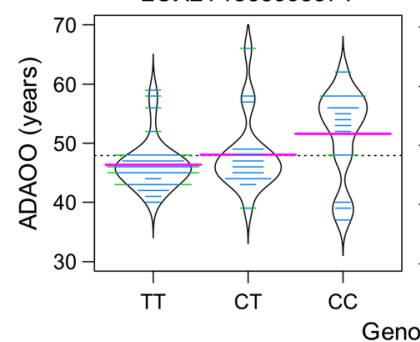

DHRS4L2-rs2273946

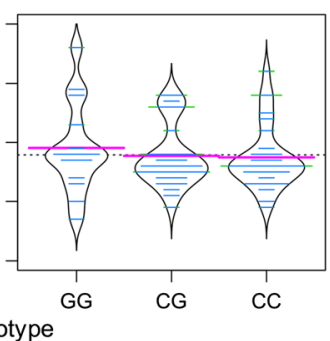

Fig 1 a Filtering process applied to exonic variants. Filter 1 includes common variants between the Illumina's Human Exome-12V1_A BeadChip and the whole-exome capture. Filter 2 excludes variants with a genotype call rate $<90 \%$, in Hardy-Weinberg disequilibrium and with one or $>2$ alleles. Filter 3 excludes variants with MAF $<1 \%$ and Filter 4 excludes those nonfunctional. A total of 49,087 CEFVs remained for analysis. b Partition of phenotypic variance for each forward inclusion (steps 1 to 10) and backward elimination (10 steps after the dotted line). The yellow vertical line marks the selected model based on the highest

locus LMEM reported that markers SLC9C1-rs9809384 and SLC9C1-rs9809404, separated by 46 base pairs and in full linkage disequilibrium, delayed $\operatorname{ADAOO}(\hat{\beta}>0$; Table $1 \mathrm{a}$ and Fig. 1c). Interestingly, marker SLC9C1-rs9809384 $\left(P=11.03 \times 10^{-15} ; P_{\mathrm{FDR}}=4.05 \times\right.$ $10^{-11}$ ) was also found to be statistically significantly associated as an ADOO modifier when a multi-locus LMEM was used, suggesting that its effect on ADAOO withstands the presence of other interacting CEFVs modifying the history of disease. Under this recessive model, the non-synonymous mutations CSN1S1-rs10030475 (CC genotype, $P=4.76 \times 10^{-9}, P_{\mathrm{FDR}}=5.43 \times 10^{-5}$ ), LOXL4rs33995374 (CC genotype, $P=3.28 \times 10^{-7}, P_{\mathrm{FDR}}=$ 0.0024), and DHRS4L2-rs2273946 (CC genotype, $P=$ $3.48 \times 10^{-7}, P_{\mathrm{FDR}}=1.9 \times 10^{-3}$ ) were also found to be ADAOO modifiers in our cohort of individuals with AD carrying the PSEN1 E280A mutation (Table 1b). Because all estimated $\beta$ coefficients are positive, the presence of two copies of the alternate allele in markers harbored in multiple posterior probability of association ( $M P P A)$. Beanplots for ADAOO as a function of genotypes in variants with $P_{\mathrm{FDR}}<0.05$ when c single- and $\mathbf{d}$ multi-locus linear mixed-effects models were used (see Table 1). Pink, blue, and dotted horizontal lines correspond, respectively, to the within genotype average ADAOO, the individuals' ADAOO, and the global average ADAOO in our sample of 71 PSEN1 E280A mutation carriers. ADAOO, Alzheimer's disease age of onset; CEFVs, common exonic functional variants

the SLC9C1, CSN1S1, and LOXL4 genes delays ADAOO up to $\sim 11, \sim 6$, and $\sim 9$ years on average, respectively ( $\hat{\beta}>0$; Table $1 \mathrm{~b}$ and Fig. 1d). In contrast, having the CC genotype in DHRS4L2-rs2273946 accelerates ADAOO by $\sim 8$ years, on average $(\hat{\beta}<0$; Table $1 \mathrm{~b}$ and Fig. $1 \mathrm{~d})$. No gender- or education-specific effects of these SNPs were found (Table 2).

\section{Biologically Related Genes}

We successfully identified seven statistically significant biological relatednesses between previously reported genes conferring susceptibility to $\mathrm{AD}$ and those found to be recessive ADAOO modifiers in our cohort (Table 3). Of particular importance are the pairwise comparisons involving $A P O E$, and those where $A P P$ is involved because of their effects on ADAOO and AD susceptibility. Additional interpretations are provided in the Supplementary Material. 
Table 1 Results of the association analysis using recessive (a) single- and (b) multi-locus linear mixed-effect models for ADAOO in 71 patients with PSEN1 E280A Alzheimer's disease

\begin{tabular}{|c|c|c|c|c|c|c|c|c|c|c|}
\hline \multirow[t]{2}{*}{ Chr } & \multirow[t]{2}{*}{ SNPa } & \multirow[t]{2}{*}{ Position } & \multirow[t]{2}{*}{ Gene } & \multicolumn{4}{|c|}{ Marker Information } & \multicolumn{3}{|c|}{ Single-locus linear mixed-effects model } \\
\hline & & & & Ref/Alt & MAF & CR & Change & $\hat{\beta}\left(\mathbf{S E}_{\hat{\beta}}\right)$ & $\boldsymbol{P}$ & $P_{\text {FDR }}$ \\
\hline 3 & rs9809384 & $111,981,878$ & SL9C1 & $\mathrm{T} / \mathrm{C}$ & 0.32 & 1 & p.Ile364Val & $9.73(1.61)$ & $8.06 \times 10^{-8}$ & $1.8 \times 10^{-3}$ \\
\hline 3 & rs9809404 & $111,981,924$ & $S L 9 C 1$ & $\mathrm{~T} / \mathrm{C}$ & 0.29 & 1 & p.Ile348Met & $10.85(1.80)$ & $8.13 \times 10^{-8}$ & $9.2 \times 10^{-4}$ \\
\hline \multicolumn{11}{|l|}{ (b) } \\
\hline \multirow[t]{2}{*}{ Chr } & SNPa & Position & Gene & \multicolumn{4}{|c|}{ Marker Information } & \multicolumn{3}{|c|}{ Multi-locus linear mixed-effects model } \\
\hline & & & & Ref/Alt & MAF & CR & Change & $\hat{\beta}\left(\mathbf{S E}_{\hat{\beta}}\right)$ & $\boldsymbol{P}$ & $P_{\text {FDR }}$ \\
\hline 3 & rs9809384 & $111,981,878$ & $S L C 9 C 1$ & $\mathrm{~T} / \mathrm{C}$ & 0.32 & 1 & p.Ile364Val & $11.03(1.06)$ & $1.77 \times 10^{-15}$ & $4.05 \times 10^{-11}$ \\
\hline 4 & rs 10030475 & $70,807,771$ & CSN1S1 & $\mathrm{C} / \mathrm{T}$ & 0.42 & 0.97 & p.Ala117Val & $6.37(0.94)$ & $4.76 \times 10^{-9}$ & $5.43 \times 10^{-5}$ \\
\hline 10 & rs33995374 & $100,020,880$ & LOXL4 & $\mathrm{C} / \mathrm{T}$ & 0.2 & 0.98 & p.Arg154Gln & $8.80(1.55)$ & $3.28 \times 10^{-7}$ & $2.4 \times 10^{-3}$ \\
\hline 14 & rs2273946 & $24,458,162$ & DHRS4L2 & $\mathrm{G} / \mathrm{C}$ & 0.32 & 0.98 & p.Gln2His & $-8.13(1.43)$ & $3.48 \times 10^{-7}$ & $1.9 \times 10^{-3}$ \\
\hline
\end{tabular}

${ }^{a}$ UCSC GRCh37/hg19 coordinates. AOO, age of onset; Chr, chromosome; SNP, single-nucleotide polymorphism; Ref/Alt, reference/alternate allele; $M A F$, minimum allele frequency; $C R$, call rate; $\hat{\beta}$, regression coefficient; $\mathrm{SE}_{\hat{\beta}}$, standard error of $\hat{\beta} ; P, P$ value; $F D R$, false discovery rate. Highlighted variants accelerate $\mathrm{ADAOO}$

\section{Discussion}

Here we show an important set of genes whose role in the pathophysiology and therapeutics of Alzheimer's disease (AD) could be further investigated. Individuals included in this study exhibit an extreme phenotype, that is, suffer from AD caused by the PSEN1 E280A fully penetrant mutation, belong to the Paisa genetic isolate and their $\mathrm{AD}$ age of onset (ADAOO) ranges from the early 30 s to the late 70 s [23]. In previous studies $[3,5,7,35]$, we successfully applied this sampling strategy using extreme phenotypes (of major effect phenotypes) [36-39]. Power estimates are included in the Supplementary Material. Briefly, using the current sample size and testing $m=100,000$ common exonic functional variants, a number that certainly exceeds the number of variants tested in this study, yields to a post hoc power estimate > 99\%.

Table 2 Gender- and education-specific effects of associated SNPs on ADAOO

\begin{tabular}{|c|c|c|c|c|c|c|c|}
\hline \multirow[t]{2}{*}{$\mathrm{Chr}$} & \multirow[t]{2}{*}{$\mathrm{SNPa}$} & \multicolumn{3}{|l|}{ Sex } & \multicolumn{3}{|c|}{ Education groupb } \\
\hline & & $x^{2}$ & $\mathrm{df}$ & $P$ & $\chi^{2}$ & $\mathrm{df}$ & $P$ \\
\hline 3 & rs9809384 & 2.532 & 2 & 0.282 & 7.373 & 4 & 0.117 \\
\hline 3 & rs9809404 & 1.269 & 2 & 0.530 & 7.373 & 4 & 0.117 \\
\hline 4 & rs 10030475 & 0.255 & 2 & 0.880 & 2.538 & 4 & 0.638 \\
\hline 10 & rs33995374 & 1.239 & 2 & 0.538 & 3.317 & 4 & 0.506 \\
\hline 14 & rs2273946 & 1.239 & 2 & 0.538 & 3.317 & 4 & 0.506 \\
\hline
\end{tabular}

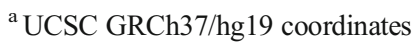

b Includes "no," "primary," "middle," and "tertiary" education

$A D A O O$, Alzheimer's disease age of onset; Chr, chromosome; SNP, single-nucleotide polymorphism. $\chi^{2}$, test statistic; $d f$, degrees of freedom
We identified that variants harbored within the Solute Carrier Family 9 Member C1 ( $S L C 9 C 1)$, the Casein Alpha S1 (CSN1S1), and the Lysyl Oxidase Like 4 (LOXL4) genes delay the $\mathrm{AD}$ age of onset (ADAOO) up to $\sim 11$ years. In contrast, a non-synonymous variant harbored in the Dehydrogenase/Reductase 4 Like 2 (DHRS4L2) gene accelerates ADAOO up to $\sim 8$ years (Table 1). To the best of our knowledge, this is the first time that variants within the genes reported herein either delay or accelerate ADAOO under a recessive oligogenic model in individuals with familiar $\mathrm{AD}$ caused by a fully penetrant mutation.

The $S L C 9 C 1$ gene, located at 3q13.2, has a cell membrane sub-cellular localization, and has been related with an ion channel activity and maintenance of the acid-base homeostasis [40]. Molecules with this role have been linked with several pathologies, such as cancer, where there is an aberrant regulation of hydrogen ion dynamics leading to $\mathrm{pH}$ disruption in a variety of cells and tissues. Genes such as $S L C 9 C 1$ have been use to downregulate $\mathrm{pH}$ regulation capacity on cancer cells [41]. SLC9C1 is expressed in the brain, the cortex, and the cerebellum [42]. We hypothesized that, because of its antiporter activity, SLC9C1 could enable the balance of the cell/tissue $\mathrm{pH}$ and influence the transport of solutes and molecules across the membrane, cleaning up the debris or surplus molecules deposited in E280A affected neurons, allowing them to survive longer due perhaps to the positive activity of $S L C 9 C 1$. Moreover, its ortholog-DNhe2 in Drosophila - has shown to control intracellular $\mathrm{pH}$ and to induce adult epithelial and embryonic stem cell differentiation [43], an important feature that enable cell renewal that could potentially induced cell-replacement in affected cells.

Gene ontology analyses indicate that CSN1S1 plays an important role in the capacity of milk to transport calcium phosphate. It is intriguing that $C S N 1 S 1$ is biologically related to the 
Table 3 Statistically significant biological relatedness between $\mathrm{AD}$ core genes and those (target genes) identified as ADAOO modifiers

\begin{tabular}{lllll}
\hline AD gene & Target & Distancea & $\boldsymbol{P}$ & Route \\
\hline$A P O E$ & CSN1S1 & 6.0 & 0.0109 & APOE [1.25] CSNK2A1 [1.76] CSN1S1 \\
$C L U$ & CSN1S1 & 7.0 & 0.0226 & $C L U[1.755]$ CUL1 [1.74] CSN1S1 \\
$A P P$ & DHRS4L2 & 10.2 & 0.0274 & $A P P[1.74]$ UBC [3.38] DHRS4L2 \\
$A P P$ & LOXL4 & 10.2 & 0.0279 & $A P P[1.74]$ UBC [3.38] LOXL4 \\
$C L U$ & SLC9C1 & 17.6 & 0.0289 & $C L U[1.25]$ HRAS [1.25] BRAP [3.37] SLC9C1 \\
APOE & DHRS4L2 & 10.2 & 0.0329 & APOE [1.74 ]UBC [3.38] DHRS4L2 \\
APOE & LOXL4 & 10.2 & 0.0335 & APOE [1.74] UBC [3.38] LOXL4 \\
\hline
\end{tabular}

${ }^{a}$ Calculated as in Itan et al. [34]. $A D$, Alzheimer's disease; $A P O E=$ apolipoprotein E; $A P P$, amyloid beta precursor protein; $B R A P$, BRCA1 associated protein; $C L U$, clusterin; $C S N 1 S 1$, casein alpha $\mathrm{S} 1 ; C S N K 2 A 1$, casein kinase 2 alpha 1; DHRS4L2, dehydrogenase/reductase 4 Like 2; HRAS, HRas proto-oncogene, GTPase; LOXL4, lysyl oxidase like 4; $S L C 9 C 1$, solute carrier family 9 member C1; $U B C$, ubiquitin C; $P, P$ value. Values within [] correspond to the direct biological distance between genes. For more details, see the "Materials and Methods" section in [34]
Apolipoprotein E $(A P O E)$ and Clusterin $(C L U)$ genes (Table 2), which have been shown to delay ADAOO in PSEN1 E280A mutation carriers and as a mediator of $\mathrm{A} \beta$ toxicity with neuroprotective effects, respectively $[5,35,44]$. Epidemiological studies suggest that intake of milk and fermented dairy products are significantly associated with a decreased risk of $\mathrm{AD}$, cognitive decline, and cognitive-related disorders in the elderly [45-49]. A mouse model of AD fed with camembert cheese, which was obtained from sterilized milk fermented with Lactococcus lactis to reduce the $\mathrm{pH}$ and subsequently with Penicillium candidum, showed both significantly reduced levels of amyloid $\beta(\mathrm{A} \beta)$ accumulation and hippocampal inflammation, and enhancing hippocampal neurotrophic factors [50]. These results provide supporting biological and molecular evidence on the preventive effects of milkderived products on $\mathrm{AD}$ susceptibility, which were reported only epidemiologically. Finding that PSEN1 mutation carriers with the CC recessive genotype in CSN1S1-rs10030475 have a $\sim 6$-year delay on the ADOO (Table 1 and Fig. 1d) sheds some light into developing new therapeutic alternatives against $\mathrm{AD}$ focused on nutrigenomic research [51-53].

$L O X L 4$ belongs to a family of five copper-dependent amine oxidases including LOX, LOXL, LOXL2, LOXL3, and LOXL4. These genes have been shown to be involved in extracellular matrix (ECM) formation, founding the crosslinking between collagen and elastin [54]. LOXL4 has been reported to be responsible for the lysine-derived cross-links toward collagen and elastin, essential in biogenesis of extracellular matrix. However, the LOX family has several other functions important in cancer progression such as cell growth, cell adhesion, migration, and invasion [55]. Perhaps, LOXL4 proliferative migratory activity could influence PSEN1-affected cells and modify their ECM components through the activation of Src/FAK signaling axis, which controls epithelial morphology $[55,56]$. LOXL4 ECM induced plasticity as well as induction of proliferative activity could lead to a better physiological stability of PSEN1-mutated cells, which results in the ADAOO delaying effect observed in these patients. This effect is in line with the delayer effect of the $A P O E^{*} E 2$ allele in this cohort $[5,35]$. Given the biological relatedness between $A P O E$ and $L O X L 4$ (Table 3), the synergistic effect of these two genes on ADAOO is yet to be elucidated.

A non-synonymous variant within the DHRS4L2 gene that accelerates ADAOO was identified (rs2273946, $P=3.48 \times 10^{-7}$, $P_{\mathrm{FDR}}=1.9 \times 10^{-3}$; Table 1$)$. This result suggests that DHRS4L2 activity in PSEN1 mutation carriers is directly associated with alterations of the proteolytic $\gamma$-secretase subunit, which is fundamental to cleave many transmembrane proteins. DHRS4L2 is expressed in the brain-the cortex and the cerebellum-[42] and belongs to the SDR enzyme family. They have shown to play a role in the NAD/NADP-dependentdehydrogenasereductases(NRDR) activity on a large and heterogeneous set of substrates including steroids, retinoid, prostaglandins, metabolites, and xenobiotics [57]. We hypothesize that, as a consequence of such alterations, more $A \beta$ plaques accumulate in the CNS and neurons apoptosis is subsequently initiated. Thus, misregulation of DHRS4L2 could exacerbate the AD phenotype, ultimately leading to the appearance $\mathrm{AD}$ sign and symptoms at early ages in PSEN1 mutation carriers. DHRS4L2 enzyme has been shown to reduce endogenous products, such as prostaglandins, biogenic aldehydes, steroids, reactive lipid peroxidation products, and xenobiotic compounds (i.e., pharmacologic drugs, carcinogens, and toxicants), suggesting that NRDR may be implicated in the metabolism and detoxification of carbonyl compounds [58]. Action of dehydrogenase alteration has also been linked to neurodegeneration process, due to increased toxic aldehydes. Such dysregulation in dehydrogenase activity has shown to increase cytotoxicity, oxidative stress, energy deficits, apoptosis, and cell death [59]. Interestingly, Li et al. (2012) [58] found a natural antisense transcript, the long noncoding RNA (lncRNA) AS1DHRS4, which lies on the opposite strand of DHRS4, and the $5^{\prime}$ ends of the genes overlap. The authors showed that silencing ASIDHRS4 resulted in both increased mRNA and protein expression of DHRS4, and increased mRNA expression of DHRS4L1 and DHRS4L2. The control exerted by this lncRNA 
on DHRS4L2 highlights the importance of this gene in the homeostasis and cell balance in AD. Moreover, the biological relatedness between DHRS4L2 and APP(Table 3), a gene harboring recessive mutations causing $\mathrm{AD}$ [15-19], reinforces the importance of further studying the accelerating effect on the ADAOO of this variant within DHRSAL2 in other AD populations.

Considering that no current effective treatment to slow or even stop $\mathrm{AD}$ progression is available, human-induced pluripotent stem cells (iPSCs), which have greatly facilitated the generation of patient-specific neurons to study patientspecific characteristics in AD [60], represent a new way of assessing the patient-specific basis of disease and what the effect would be when particular changes are introduced. Future validation studies of our findings are needed. Such studies, we propose, will greatly benefit from using iPSCs coming from PSEN1 E280A mutation carriers [61] to investigating the over expression and downregulation of some of these ADAOO recessive modifier variants and better understand the pathogenesis of the $\mathrm{AD}$ in our patients, as well as the potential development of new therapeutic targets for AD.

In summary, here we identified recessive mutations shaping the natural history of $\mathrm{AD}$ in members of a multigenerational extended family carrying the PSEN1 E280A mutation. In this regard, it is important to highlight that, because the set of individuals carrying the PSEN1 E280 mutation in this study and those analyzed in Vélez et al [5] are the same, both studies are highly correlated. However, in the current study, we explore whether recessive variants may explain $\mathrm{ADAOO}$ variability. As demonstrated by this study, new important themes, once missed by the dominant and codominant of transmission, were strongly associated to the ADAOO. Although previous studies have provided conclusive evidence that recessive genetic variations within increase $\mathrm{AD}$ susceptibility and cause $\mathrm{AD}$ in Caucasian and Japanese populations [15-19], our results suggest that-high order recessive genetic interactions between PSEN1 and the set of genes reported herein have a significant modifier effect on $\mathrm{ADAOO}$ in individuals with $\mathrm{AD}$ from the Paisa genetic isolate.

Acknowledgments We express our highest sentiment of appreciation to all patients and their relatives enrolled in this study for more than 30 years.

Role of Funding Source The sponsors of the study have no role in the study design, data collection, data analysis, data interpretation, or writing of the reports. JIV, CAM, FL and MAB have full access to all the data in the study. JIV and MAB are responsible for submitting this work for publication.

Availability of Data and Materials The datasets used and/or analyzed during the current study are available from the corresponding author on reasonable request.

Funding Information This study was financed by a starting package allocated to MAB by the Australian National University to launch his laboratory, and COLCIENCIAS and the University of Antioquia, grant 1115-408-20543.

\section{Compliance with Ethical Standards}

Consent for Publication All authors have read the manuscript and approved the final version for publication.

Competing Interests The authors declare that they have no conflicts of interest.

Open Access This article is distributed under the terms of the Creative Commons Attribution 4.0 International License (http:// creativecommons.org/licenses/by/4.0/), which permits unrestricted use, distribution, and reproduction in any medium, provided you give appropriate credit to the original author(s) and the source, provide a link to the Creative Commons license, and indicate if changes were made.

\section{References}

1. Prince M, Bryce R, Albanese E, Wimo A, Ribeiro W, Ferri CP (2013) The global prevalence of dementia: a systematic review and metaanalysis. Alzheimers Dement 9(1):63-75 e62. https://doi. org/10.1016/j.jalz.2012.11.007

2. Brookmeyer R, Kawas CH, Abdallah N, Paganini-Hill A, Kim RC, Corrada MM (2016) Impact of interventions to reduce Alzheimer's disease pathology on the prevalence of dementia in the oldest-old. Alzheimers Dement 12(3):225-232. https://doi.org/10.1016/j.jalz. 2016.01.004

3. Velez JI, Lopera F, Patel HR, Johar AS, Cai Y, Rivera D, Tobon C, Villegas A et al (2016) Mutations modifying sporadic Alzheimer's disease age of onset. Am J Med Genet B Neuropsychiatr Genet 171(8):1116-1130. https://doi.org/10.1002/ajmg.b.32493

4. Velez JI, Rivera D, Mastronardi CA, Patel HR, Tobon C, Villegas A, Cai Y, Easteal S et al (2016) A mutation in DAOA modifies the age of onset in PSEN1 E280A Alzheimer's disease. Neural Plast 2016:9760314. https://doi.org/10.1155/2016/9760314

5. Velez JI, Lopera F, Sepulveda-Falla D, Patel HR, Johar AS, Chuah A, Tobon C, Rivera D et al (2016) APOE*E2 allele delays age of onset in PSEN1 E280A Alzheimer's disease. Mol Psychiatry 21(7): 916-924. https://doi.org/10.1038/mp.2015.177

6. Lalli MA, Garcia G, Madrigal L, Arcos-Burgos M, Arcila ML, Kosik KS, Lopera F (2012) Exploratory data from complete genomes of familial Alzheimer disease age-at-onset outliers. Hum Mutat 33(12):1630-1634. https://doi.org/10.1002/humu.22167

7. Velez JI, Chandrasekharappa SC, Henao E, Martinez AF, Harper U, Jones M, Solomon BD, Lopez L et al (2013)Pooling/bootstrapbased GWAS (pbGWAS) identifies new loci modifying the age of onset in PSEN1 p.Glu280Ala Alzheimer's disease. Mol Psychiatry 18(5):568-575. https://doi.org/10.1038/mp.2012.81

8. Molero AE, Pino-Ramirez G, Maestre GE (2001) Modulation by age and gender of risk for Alzheimer's disease and vascular dementia associated with the apolipoprotein E-epsilon4 allele in Latin Americans: findings from the Maracaibo Aging Study. Neurosci Lett 307(1):5-8

9. Lee JH, Cheng R, Vardarajan B, Lantigua R, Reyes-Dumeyer D, Ortmann W, Graham RR, Bhangale T et al (2015) Genetic modifiers of age at onset in carriers of the G206A mutation in PSEN1 with familial Alzheimer disease among Caribbean Hispanics. JAMA Neurol 72(9):1043-1051. https://doi.org/10.1001/ jamaneurol.2015.1424

10. Deming Y, Li Z, Kapoor M, Harari O, Del-Aguila JL, Black K, Carrell D, Cai Y et al (2017)Genome-wide association study identifies four novel loci associated with Alzheimer's endophenotypes 
and disease modifiers. Acta Neuropathol 133(5):839-856. https:// doi.org/10.1007/s00401-017-1685-y

11. Arcos-Burgos M, Muenke M (2002) Genetics of population isolates. Clin Genet 61(4):233-247

12. Lopera F, Ardilla A, Martinez A, Madrigal L, Arango-Viana JC, Lemere CA, Arango-Lasprilla JC, Hincapie L et al (1997) Clinical features of early-onset Alzheimer disease in a large kindred with an E280A presenilin-1 mutation. JAMA 277(10):793-799

13. Londono AC, Castellanos FX, Arbelaez A, Ruiz A, AguirreAcevedo DC, Richardson AM, Easteal S, Lidbury BA et al (2014) An 1H-MRS framework predicts the onset of Alzheimer's disease symptoms in PSEN1 mutation carriers. Alzheimers Dement 10(5):552-561. https://doi.org/10.1016/j.jalz.2013.08.282

14. Lopera F, Rivera N, Arboleda J, Restrepo T, Arcos-Burgos M (2001) Analysis of complex segregation in a large family with hereditary cerebrovascular disease in Antioquia, Colombia. Rev Neurol 32(3):222-225

15. Cabrejo L, Guyant-Marechal L, Laquerriere A, Vercelletto M, De la Fourniere F, Thomas-Anterion C, Verny C, Letournel F et al (2006) Phenotype associated with APP duplication in five families. Brain 129(Pt 11):2966-2976. https://doi.org/10.1093/brain/awl237

16. Di Fede G, Catania M, Morbin M, Rossi G, Suardi S, Mazzoleni G, Merlin M, Giovagnoli AR et al (2009) A recessive mutation in the APP gene with dominant-negative effect on amyloidogenesis. Science 323(5920):1473-1477. https://doi.org/10.1126/science. 1168979

17. Rovelet-Lecrux A, Hannequin D, Raux G, Le Meur N, Laquerriere A, Vital A, Dumanchin C, Feuillette S et al (2006) APP locus duplication causes autosomal dominant early-onset Alzheimer disease with cerebral amyloid angiopathy. Nat Genet 38(1):24-26. https://doi.org/10.1038/ng1718

18. Sleegers K, Brouwers N, Gijselinck I, Theuns J, Goossens D, Wauters J, Del-Favero J, Cruts M et al (2006) APP duplication is sufficient to cause early onset Alzheimer's dementia with cerebral amyloid angiopathy. Brain 129(Pt 11):2977-2983. https://doi.org/ 10.1093/brain/awl203

19. Tomiyama T, Nagata T, Shimada H, Teraoka R, Fukushima A, Kanemitsu H, Takuma H, Kuwano R et al (2008) A new amyloid beta variant favoring oligomerization in Alzheimer's-type dementia. Ann Neurol 63(3):377-387. https://doi.org/10.1002/ana.21321

20. Mani A, Meraji SM, Houshyar R, Radhakrishnan J, Mani A, Ahangar M, Rezaie TM, Taghavinejad MA et al (2002) Finding genetic contributions to sporadic disease: a recessive locus at 12q24 commonly contributes to patent ductus arteriosus. Proc Natl Acad Sci U S A 99(23):15054-15059. https://doi.org/10.1073/pnas. 192582999

21. Afgin AE, Massarwa M, Schechtman E, Israeli-Korn SD, Strugatsky R, Abuful A, Farrer LA, Friedland RP et al (2012) High prevalence of mild cognitive impairment and Alzheimer's disease in arabic villages in northern Israel: impact of gender and education. J Alzheimers Dis 29(2):431-439. https://doi.org/10. 3233/JAD-2011-111667

22. Bowirrat A, Friedland RP, Chapman J, Korczyn AD (2000) The very high prevalence of $\mathrm{AD}$ in an Arab population is not explained by APOE epsilon4 allele frequency. Neurology 55(5):731. https:// doi.org/10.1212/wnl.55.5.731

23. Acosta-Baena N, Sepulveda-Falla D, Lopera-Gomez CM, Jaramillo-Elorza MC, Moreno S, Aguirre-Acevedo DC, Saldarriaga A, Lopera F (2011)Pre-dementia clinical stages in presenilin 1 E280A familial early-onset Alzheimer's disease: a retrospective cohort study. Lancet Neurol 10(3):213-220. https://doi. org/10.1016/S1474-4422(10)70323-9

24. Lopera F, Tobon N, Arcos-Burgos M, Vargas S, Gutierrez JE, Rosselli M, Ardila A (1999) Image characterization of Alzheimer's disease associated with the E280A-PS1 mutation. Case-control study: MRI findings. Rev Neurol 29(1):6-12
25. Bansal V, Libiger O, Torkamani A, Schork NJ (2010) Statistical analysis strategies for association studies involving rare variants. Nature reviews Genetics 11(11):773-785. https://doi.org/10.1038/ nrg2867

26. Davydov EV, Goode DL, Sirota M, Cooper GM, Sidow A, Batzoglou S (2010) Identifying a high fraction of the human genome to be under selective constraint using GERP++. PLoS Comput Biol 6(12):e1001025. https://doi.org/10.1371/journal. pcbi. 1001025

27. Adzhubei IA, Schmidt S, Peshkin L, Ramensky VE, Gerasimova A, Bork P, Kondrashov AS, Sunyaev SRA Method and server for predicting damaging missense mutations. Nat Methods 7(4):248249. https://doi.org/10.1038/nmeth0410-248

28. Ng PC, Henikoff S (2003) SIFT: predicting amino acid changes that affect protein function. Nucleic Acids Res 31(13):3812-3814

29. Schwarz JM, Rodelsperger C, Schuelke M, Seelow D (2010) MutationTaster evaluates disease-causing potential of sequence alterations. Nat Methods 7(8):575-576. https://doi.org/10.1038/ nmeth0810-575

30. Segura V, Vilhjalmsson BJ, Platt A, Korte A, Seren U, Long Q, Nordborg M (2012) An efficient multi-locus mixed-model approach for genome-wide association studies in structured populations. Nat Genet 44(7):825-830. https://doi.org/10.1038/ng.2314

31. Benjamini Y, Hochberg Y (1995) Controlling the false discovery rate: a practical and powerful approach to multiple testing. J R Stat Soc B 57(1):289-300

32. Vélez JI, Correa JC, Arcos-Burgos M (2014) A new method for detecting significant p-values with applications to genetic data. Rev Colomb Estad 37(1):67-76

33. R Core Team (2019) R: A language and environment for statistical computing. R Foundation for Statistical Computing, Vienna, Austria. URL: http://www.R-project.org.

34. Itan Y, Zhang SY, Vogt G, Abhyankar A, Herman M, Nitschke P, Fried D, Quintana-Murci L et al (2013) The human gene connectome as a map of short cuts for morbid allele discovery. Proc Natl Acad Sci U S A 110(14):5558-5563. https://doi.org/10. 1073/pnas.1218167110

35. Vélez JI, Lopera F, Creagh PK, Pineros LB, Das D, CervantesHenriquez ML, Acosta-Lopez JE, Isaza-Ruget MA et al (2019) Targeting neuroplasticity, cardiovascular, and cognitive-associated genomic variants in familial Alzheimer's disease. Mol Neurobiol 565)3235-3243. https://doi.org/10.1007/s12035-018-1298-z

36. Barnett IJ, Lee S, Lin X (2013) Detecting rare variant effects using extreme phenotype sampling in sequencing association studies. Genet Epidemiol 37(2):142-151. https://doi.org/10.1002/gepi. 21699

37. Emond MJ, Louie T, Emerson J, Zhao W, Mathias RA, Knowles MR, Wright FA, Rieder MJ et al (2012) Exome sequencing of extreme phenotypes identifies DCTN4 as a modifier of chronic Pseudomonas aeruginosa infection in cystic fibrosis. Nat Genet 44(8):886-889. https://doi.org/10.1038/ng.2344

38. Johar AS, Anaya JM, Andrews D, Patel HR, Field M, Goodnow C, Arcos-Burgos M (2015) Candidate gene discovery in autoimmunity by using extreme phenotypes, next generation sequencing and whole exome capture. Autoimmun Rev 14(3):204-209. https:// doi.org/10.1016/j.autrev.2014.10.021

39. Paz-Filho G, Boguszewski MC, Mastronardi CA, Patel HR, Johar AS, Chuah A, Huttley GA, Boguszewski CL et al (2014) Whole exome sequencing of extreme morbid obesity patients: translational implications for obesity and related disorders. Genes (Basel) 5(3): 709-725. https://doi.org/10.3390/genes5030709

40. Fuster DG, Alexander RT (2014) Traditional and emerging roles for the SLC9 Na+/H+ exchangers. Pflugers Arch 466(1):61-76. https:// doi.org/10.1007/s00424-013-1408-8

41. Harguindey S, Arranz JL, Polo Orozco JD, Rauch C, Fais S, Cardone RA, Reshkin SJ (2013) Cariporide and other new and 
powerful NHE1 inhibitors as potentially selective anticancer drugs-an integral molecular/biochemical/metabolic/clinical approach after one hundred years of cancer research. J Transl Med 11:282. https://doi.org/10.1186/1479-5876-11-282

42. Velculescu VE, Zhang L, Vogelstein B, Kinzler KW (1995) Serial analysis of gene expression. Science 270(5235):484-487. https:// doi.org/10.1126/science.270.5235.484

43. Ulmscheneider B, Grillo-Hill BK, Benitez M, Azimova DR, Barber DL, Nystul TG (2016) Increased intracellular $\mathrm{pH}$ is necessary for adult epithelial and embryonic stem cell differentiation. J Cell Biol 215(3):345-355. https://doi.org/10.1083/jcb.201606042

44. Foster EM, Dangla-Valls A, Lovestone S, Ribe EM, Buckley NJ (2019) Clusterin in Alzheimer's disease: mechanisms, genetics, and lessons from other pathologies. Front Neurosci 13:164. https://doi. org/10.3389/fnins.2019.00164

45. Ano Y, Nakayama H (2018) Preventive effects of dairy products on dementia and the underlying mechanisms. Int J Mol Sci 19(7). https://doi.org/10.3390/ijms19071927

46. Camfield DA, Owen L, Scholey AB, Pipingas A, Stough C (2011) Dairy constituents and neurocognitive health in ageing. Br J Nutr 106(2):159-174. https://doi.org/10.1017/S0007114511000158

47. Crichton GE, Murphy KJ, Bryan J (2010) Dairy intake and cognitive health in middle-aged South Australians. Asia Pac J Clin Nutr 19(2):161-171

48. Ozawa M, Ninomiya T, Ohara T, Doi Y, Uchida K, Shirota T, Yonemoto K, Kitazono T et al (2013) Dietary patterns and risk of dementia in an elderly Japanese population: the Hisayama Study. Am J Clin Nutr 97(5):1076-1082. https://doi.org/10.3945/ajcn.112. 045575

49. Wu L, Sun D (2016)Meta-analysis of milk consumption and the risk of cognitive disorders. Nutrients 8(12). https://doi.org/10.3390/ nu8120824

50. Ano Y, Ozawa M, Kutsukake T, Sugiyama S, Uchida K, Yoshida A, Nakayama H (2015) Preventive effects of a fermented dairy product against Alzheimer's disease and identification of a novel oleamide with enhanced microglial phagocytosis and anti-inflammatory activity. PLoS One 10(3):e0118512. https://doi.org/10.1371/journal. pone. 0118512

51. Athanasopoulos D, Karagiannis G, Tsolaki M (2016) Recent findings in Alzheimer disease and nutrition focusing on epigenetics. Adv Nutr 7(5):917-927. https://doi.org/10.3945/an.116.012229

52. Cacabelos R (2005) Pharmacogenomics, nutrigenomics and therapeutic optimization in Alzheimer's disease. Aging Health 1(2):303348
53. Lee S, Thomas P, Fenech M (2012) Nutrigenomic biomarkers for increased risk of mild cognitive impairment and Alzheimer's disease. Alzheimer's \& Dementia 8(4):P476. https://doi.org/10.1016/j. jalz.2012.05.1283

54. Li RK, Zhao WY, Fang F, Zhuang C, Zhang XX, Yang XM, Jiang SH, Kong FZ et al (2015) Lysyl oxidase-like 4 (LOXL4) promotes proliferation and metastasis of gastric cancer via FAK/Src pathway. J Cancer Res Clin Oncol 141(2):269-281. https://doi.org/10.1007/ s00432-014-1823-Z

55. Yang N, Li S, Li G, Zhang S, Tang X, Ni S, Jian X, Xu C et al (2017) The role of extracellular vesicles in mediating progression, metastasis and potential treatment of hepatocellular carcinoma. Oncotarget 8(2):3683-3695. https://doi.org/10.18632/oncotarget. 12465

56. Serrels A, Canel M, Brunton VG, Frame MC (2011)Src/FAKmediated regulation of E-cadherin as a mechanism for controlling collective cell movement: insights from in vivo imaging. Cell Adh Migr 5(4):360-365. https://doi.org/10.4161/cam.5.4.17290

57. Gabrielli F, Tofanelli S (2012) Molecular and functional evolution of human DHRS2 and DHRS4 duplicated genes. Gene 511(2):461469. https://doi.org/10.1016/j.gene.2012.09.013

58. Li Q, Su Z, Xu X, Liu G, Song X, Wang R, Sui X, Liu T et al (2012) AS1DHRS4, a head-to-head natural antisense transcript, silences the DHRS4 gene cluster in cis and trans. Proc Natl Acad Sci U S A 109(35):14110-14115. https://doi.org/10.1073/pnas. 1116597109

59. Marchitti SA, Brocker C, Stagos D, Vasiliou V (2008)Non-P450 aldehyde oxidizing enzymes: the aldehyde dehydrogenase superfamily. Expert Opin Drug Metab Toxicol 4(6):697-720. https://doi. org/10.1517/17425255.4.6.697

60. Mungenast AE, Siegert S, Tsai LH (2016) Modeling Alzheimer's disease with human induced pluripotent stem (iPS) cells. Mol Cell Neurosci 73:13-31. https://doi.org/10.1016/j.mcn.2015.11.010

61. Vallejo-Diez S, Fleischer A, Martin-Fernandez JM, SanchezGilabert A, Castresana M, Aguillon D, Villegas A, Mastronardi CA et al (2019) Generation of one iPSC line (IMEDEAi006-A) from an early-onset familial Alzheimer's Disease (fAD) patient carrying the E280A mutation in the PSEN1 gene. Stem Cell Res 37:101440. https://doi.org/10.1016/j.scr.2019.101440

Publisher's Note Springer Nature remains neutral with regard to jurisdictional claims in published maps and institutional affiliations. 